\title{
Copyright Explainer What Is a Tangible Medium?
}

Benjamin J. Keele, Indiana University Robert H. McKinney School of Law

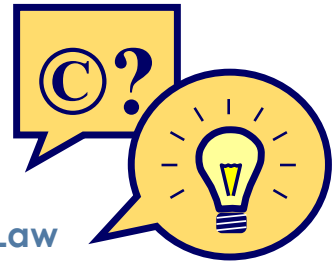

$\mathrm{I}$ $\mathrm{n}$ my last column, we discussed the Copyright Act's requirement that a work be fixed (a computer's RAM may count, but not one's mind) to be protected by copyright. This time, I would like to think about what the work must be fixed in: "a tangible medium of expression, now known or later developed." 17 U.S.C. § 102. How does this tangible medium of expression requirement distinguish between what can be copyrighted and what cannot? Most of the items libraries purchase and license (books, journals, digital collections) are undoubtedly fixed in tangible media, but there are some examples that show the tangible medium requirement does exclude some things.

Speeches and performances, unless recorded in some way, are not fixed. Suppose, in my legal research class, I gave what I thought was a particularly novel and well-put explanation of the administrative rulemaking process. One of my colleagues observed my presentation and then incorporated my explanation into her next class on administrative law. Could I say she had infringed my copyright on my discussion of rulemaking?

Strange that I am so petty in my own hypothetical, but in any event I cannot claim copyright in my class presentation because I did not record it on any tangible medium. Perhaps I could have made an audio or video recording, or I could have transcribed what I said, and then I would have a copyrighted work. If I want to copyright a performance, I must record it in some way.

This recording requirement applies to economically valuable performances. An amusing example is Conrad v. AM Community Credit Union, 750 F.3d 634 (7th Cir. 2014) (those looking up the case will be rewarded with a photo of the plaintiff in her banana costume). Conrad,
[The Banana Lady]

had not fixed her

performance in any

angible medium . . the self-anointed "Banana Lady," performed a singing telegram at a trade event. When observers took and posted online pictures and videos of her performance, she sued the organizer for copyright infringement. Judge Posner, writing for the panel, said she had not fixed her performance in any tangible medium and thus had no copyright.

The tangible medium requirement has also impeded copyright protection for more high-brow performances, including dance choreography, yoga postures, and exercise routines. I recommend Jodi Collova's Beyond Bikram: Stretching the Definition of Choreographic Works, 1 Legal Information Rev. 75 (2015-2016), for a discussion of how copyright treats modern dance choreography, an art that embraces its improvisational and ephemeral nature.

The tangible medium requirement, thankfully, helps shield people talking about last night's football game from claims of infringement. While the National Football League (NFL) solemnly announces that no accounts of the game may be distributed without its permission, the football game itself is not fixed in any tangible form. The NFL may have copyright in the video recordings of the game, but that copyright covers one recording of the game, not all possible accounts and description of what happened in that stadium.

From a copyright perspective, for speeches, performances, and events, there needs to be a recording that can be later accessed and communicated. Otherwise, the work - the word and actions - will only live on freely in observers' memories.

If you have any thoughts or questions about copyright and libraries, please contact me at bkeele@iu.edu. 